\title{
MISCELLANEA
}

\section{Preliminary Communication: A Physiological Study of the Effects of Vibration on the Fingers}

\section{LADISLAUS MAGOS}

From the State Institute of Occupational Medicine, Department of Industrial Hygiene, Budapest

(RECEIVED FOR PUBLICATION FEBRUARY 19, 1960)

It has been well known for many years that the long-continued use of certain vibrating tools may lead to the development of Raynaud's phenomenon. Much is known about the clinical aspects of vibratory Raynaud's phenomenon (see, for example, Agate, 1949), but it is not known how the vibration causes this disability. An important study was undertaken by Guillemin and Wechsberg (1953), who found that, after 1,000 hours' exposure to vibration, the rewarming time of albino rats exceeded the normal value.

In our experiments the physiological effect of a short exposure to mechanical vibration was measured on the forefinger. As a physiological test, the Lewis reaction (cold dilatation) was chosen. This reaction, according to Magos and Okos $(1955 ; 1956)$ is diminished or abolished in patients suffering from Raynaud's phenomenon.

\section{Method}

Nine men giving identical results in the cold dilatation test on both index fingers were selected. Six of them $(20,25,30,34,36$, and 53 years of age) showed no disorder of peripheral circulation, and three $(27,33$, and 42 years of age) suffered from vibratory Raynaud's phenomenon.

Calorimetric examination by Greenfield and Shepherd's (1950) method was undertaken. The distal $2.8 \mathrm{~cm}$. of the index finger was placed in water in the calorimeter at $9 \cdot 5^{\circ} \mathrm{C}$. for 15 minutes. In every experiment at least four calorimetric measurements were made, two of them the day before the vibratory procedure, one after the vibration was applied to the exposed finger, and one on the opposite (control) finger.

The vibratory exposure was made with a plate vibrated vertically by an eccentric wheel at 3,000 cycles per minute with an amplitude of $2 \mathrm{~mm}$. The subjects placed the palmar surface of the terminal phalanx of one index finger on this plate for 10 minutes. After this vibration the subjects immersed both hands completely in a water bath at $25^{\circ} \mathrm{C}$. for 10 minutes. The water bath immersion was immediately followed by calorimetric examination. In the experiment undertaken on the day before vibration the calorimetric examination was also preceded by immersion of the hands in a water bath at $25^{\circ} \mathrm{C}$. Six subjects (three healthy and three suffering from vibratory Raynaud's phenomenon) were examined in this experiment once, two subjects twice, and one three times.

In the second experimental series the application of vibration was followed by a rest of five minutes. The index finger was then immersed in the calorimeter without previous immersion in the water bath. The circulation of the vibrated finger and of the control finger was arrested by a rubber ring during the first six minutes of the calorimetric examination. In this experiment two subjects were examined once and one three times; all three were from the group without circulatory disorders.

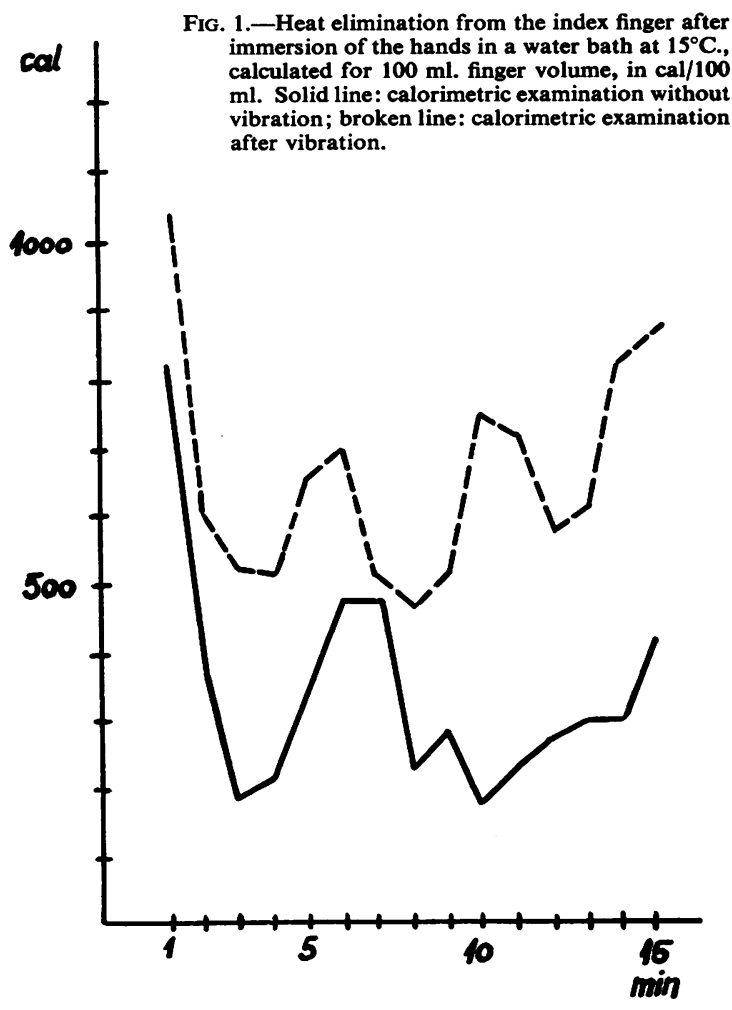




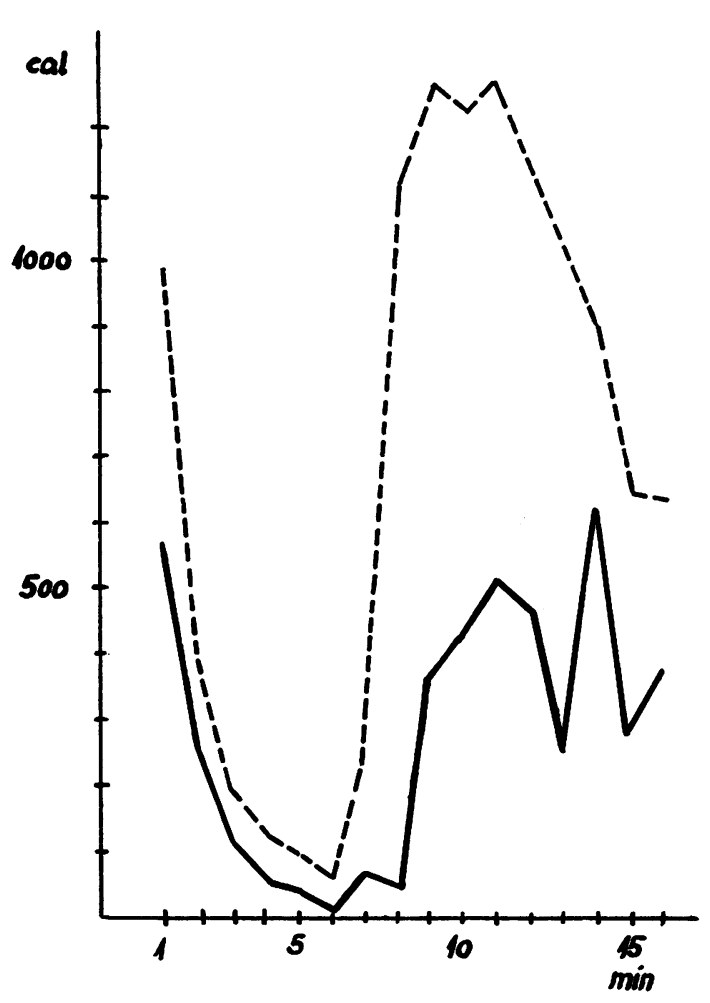

FIG. 2.-Heat elimination from the index finger, calculated for $100 \mathrm{ml}$. finger volume, in cal $/ 100 \mathrm{ml}$. During the first six minutes the circulation was arrested. Solid line: without vibration; broken line: after vibration.

\section{Results}

It was found that the heat elimination during the initial constriction and the cold dilatation was greater after the application of vibration than before; heat elimination was greater than in the opposite (control) finger. This observation was also found when the circulation was arrested during the first six minutes. Figs. 1 and 2 show typical examples of the two experimental series.

In contrast to healthy subjects, three patients suffering from vibratory Raynaud's phenomenon gave a negative response to vibration. Their heat output both in the initial phase and the second phase of the calorimetric examination remained at a very low level.

\section{Comments}

It appears from the present study that vibration causes an increase of the internal temperature of the vibrated finger and a change in the reactivity of the blood vessels to cold (increased cold dilatation). It is likely that at the beginning of the exposure to vibration, the finger blood vessels of subjects who are not accustomed to use vibrating tools show a better defence against local cooling than those with vibratory exposure. The former react with increased cold dilatation, at least immediately after the brief vibration. Subsequently, in those who work regularly with vibrating tools, the cold dilatation decreases and the blood vessels give a negative response to vibration.

It appears from this study that the increased internal temperature of the vibrated finger is a reactive effect; as is shown by the fact that in patients suffering from Raynaud's phenomenon this effect was abolished.

It is possible that vibration stimulates the same mechanism that is responsible for the cold dilatation and that long-term repetitive stimulation causes damage to this mechanism.

\section{REFERENCES}

Agate, J. N. (1949). Brit. J. industr. Med., 6, 144. Greenfield, A. D. M., and Shepherd, J. T. (1950). Clin. Sci., 9, 323. Guillemin, V. Jr., and Wechsberg, P. (1953). J. Aviat. Med., 24, 208. Magos, L., and Okos, G. (1955). Acta. med. Acad. Sci. hung., 7, 323. - , (1956). Ibid., 9, 321.

\section{Expired Air Resuscitation in a Contaminated Atmosphere}

\author{
W. M. DIXON, A. WARD GARDNER, AND \\ B. G. B. LUCAS \\ From the Medical Department, Esso Petroleum Co., Ltd., \\ Fawley, and the Surgical Unit, University College \\ Hospital Medical School, London, W.C.1
}

(RECEIVED FOR PUBLICATION JANUARY 9, 1961)

Respiratory resuscitation in an atmosphere deficient in oxygen, or heavily contaminated with poisonous substances, is a problem which may occur in some industries, and particularly in the petroleum industry. Manual methods of artificial respiration are unsuitable for obvious reasons. Either the victim has to be removed from the poisonous atmosphere before resuscitation can begin, when it may be too late, or some form of positive pressure breathing apparatus, using oxygen or compressed air, has to be employed. The latter is heavy, or may be limited in its use by the length of pipeline.

In recent years direct expired air resuscitation has been shown to be a satisfactory method of artificial respiration (Safar, Escarraga, and Elam, 1958), and it is known that this can be performed efficiently by an operator who is wearing a modified anti-gas respirator (Lucas and Whitcher, 1958). Men working in contaminated atmospheres wear some form of breathing apparatus, and modifications to a standard, open circuit, compressed air breathing set were therefore effected so that it could be used for expired air resuscitation.

Most respiratory facepieces have a plug in the side which can be used for telephonic communication. A corrugated rubber tube, 1 in. $(2.5 \mathrm{~cm}$.) in diameter, is inserted in place of this plug and projects into the 